\title{
HIV Treatment, Prevention, Surveillance and Patient Monitoring in South Africa
}

\section{Brian Williams}

South African Centre for Epidemiological Modelling and Analysis, University of Stellenbosch, South Africa: williamsbg@me.com

This document provides background information for South Africa in support of the WHO Consolidated Guidelines for Person Centered HIV Patient Monitoring and Case Surveillance ${ }^{\mathrm{i}}$

i WHO Consolidated Guidelines: http://tinyurl.com/BGW0043 


\begin{abstract}
South Africa is afflicted with the worst epidemic of HIV in the world a legacy of the system of oscillating migrant labour in the region and the consequent social disruption that was the legacy of Apartheid. The initial response from the national government was slow and ineffective but once the magnitude of the epidemic became apparent the government began to respond. The investment in HIV- and TB-related activities in 2013 was R22 Bn or (US\$2.5; 2013 exchange rate) of which the South Africa government contributed $80 \%$ and the Presidents Emergency Plan for AIDS Relief (PEPFAR) 17\%. South Africa now has the more people on anti-retroviral therapy than any other country and treatment is being started much sooner after infection. Much of the best biomedical, virological, immunological, mathematical and social science around the treatment and prevention of HIV and AIDS and the associated epidemic of TB has been done by South African's and their international collaborators.

If the efforts to control the epidemic are maintained South Africa is on track to meet the UNAIDS 90-90-90 target by 2020 and to End AIDS by 2030 in spite of the magnitude of the problem. While individual, patient level data are increasingly available, especially in the Western Cape, much greater efforts need to be made to ensure that the information collected in this way is used to give feedback and support to clinic staff, to ensure that health clinics are providing the best possible service, and to individual patients and people living with HIV to ensure that they are receiving the best possible care and support. South Africa needs to make better use of the rich and detailed data that are being collected from individual clinics and their patients to identify problems or difficulties at the clinic level and to ensure that individual patients are retained on treatment, are virally suppressed and receive the best possible care and support.
\end{abstract}

\title{
Introduction
}

South Africa has more people living with HIV than any other country. The epidemic started later than in East Africa with a prevalence of only $1.1 \%$ in 1990 but rising to $16.5 \%$ in 2005 after which it has remained fairly constant in all provinces. ${ }^{i}$ In 1989, under the leadership of Horst Küstner, ${ }^{1}$ who was among the first to understand the gravity of the situation, the Department of Health carried out a survey of HIV among women attending ante-natal clinics $(\mathrm{ANC})^{2-5}$ and these were repeated annually until 2015 providing clear evidence of the rapid spread of HIV in South Africa but with substantial variation in the prevalence of HIV among the nine provinces. ${ }^{\text {i,ii }}$ The surveys show no evidence of a decline in transmission before ART became available. ${ }^{6}$

\footnotetext{
i Modelling the impact and economics of 90-90-90 https://tinyurl.com/BGW0073

ii The 2016 ANC Survey was abandoned on the advice of the World Health Organization but the surveys have now been started again with a much more extensive survey undertaken in 2017 (Puren, A. pers. com.)
} 
The rise of the HIV epidemic coincided with the transition to democracy and, in spite of early warnings, ${ }^{i}$ from some senior members of the African National Congress, the democratically elected government initially played down the severity of the epidemic ${ }^{7}$ and later denied that HIV was the cause of AIDS. ${ }^{7}$ In the year 2000, when the world was rallying in Durban ii to find ways to respond effectively to the epidemic, President Thabo Mbeki invited senior AIDS 'denialists', notably Peter Duesberg and David Rasnick, iii to present their case that HIV was not the cause of AIDS to an invited group of senior scientists. ${ }^{\text {iv }}$ Mbeki was convinced by the 'denialists' and the response to the epidemic of HIV reached a low point with the Minister of Health promoting garlic and African potatoes ${ }^{\mathrm{v}}$ as a way of boosting the immune system in those infected with HIV and promoting Virodene, an industrial solvent, as a cure for AIDS. vi,8 With the appointment of Barbara Hogan as Minister for Health in 2008, followed by Aaron Motsoaledi in 2009, the government began to provide critically needed leadership in relation to the AIDS response and South Africa now has an excellent Prevention of Mother to Child Transmission (PMTCT) programme ${ }^{9}$ and the biggest ART programme in the world.

Despite the late and initially inadequate response by the government, the magnitude of the epidemic has meant that many of the most important scientific studies have been carried out in South Africa. These include some of the first studies to show the prevention benefits of providing ART to pregnant women to protect their babies, ${ }^{10}$ of male circumcision to protect men, ${ }^{11,12}$ oral and vaginal microbicides to protect women, ${ }^{13,14}$ early community based attempts to control HIV, vii,15-20 a critical study showing that HIV increases the incidence but not the prevalence of tuberculosis $(\mathrm{TB})^{21}$ and the development of cross-sectional HIVincidence assays. ${ }^{22}$ South Africa continues to play a leading role in population based studies of HIV and TBviii, trials of a variety of interventions at the Desmond Tutu HIV and TB Centres, ${ }^{i x, x}$ the discovery and development of broadly neutralizing anti-bodies at the Centre for the AIDS Programme of Research in South Africa (CAPRISA), ${ }^{\mathrm{x}}$ and the protection of

i 'We cannot afford to allow the AIDS epidemic to ruin the realization of our dreams. Existing statistics indicate that we are at the beginning of the AIDS epidemic in our country. Unattended, however, this will result in untold damage and suffering by the end of the century.' Hani, C. Maputo AIDS Conference, Mozambique, 1990

ii 'Let us not equivocate: a tragedy of unprecedented proportions is unfolding in Africa. AIDS today in Africa is claiming more lives than the sum total of all wars, famines and floods, and the ravages of such deadly diseases as malaria. It is devastating families and communities, overwhelming and depleting health care services; and robbing schools of both students and teachers. ... Decades have been chopped from life expectancy and young child mortality is expected to more than double in the most severely affected countries of Africa. AIDS is clearly a disaster, effectively wiping out the development gains of the past decades and sabotaging the future.' Mandela N. International Conference on HIV/AIDS, Durban, July 2000

iii The AIDS Denialists https://tinyurl.com/BGW0095

iv South African Government's Controversial AIDS Panel http://www.thebody.com/content/art2783.html

v HIV/AIDS denialism in South Africa https://tinyurl.com/BGW0094

vi Virodene https://en.wikipedia.org/wiki/Virodene

vii Videos available at https://tinyurl.com/BGW0066 and https://tinyurl.com/BGW0067

viii Africa Health Research Institute https://www.ahri.org

ix Desmond Tutu HIV Centre http://www.health.uct.ac.za/fhs/research/groupings/hivcentre

x Desmond Tutu TB Centre http://www0.sun.ac.za/dttc/

xi Centre for the AIDS Programme of Research in South Africa (CAPRISA): http://www.caprisa.org/Default 
human-rights through the Treatment Action Campaign. Other key institutions dealing with HIV in South Africa include the WRHI, ${ }^{i i}$ Right-to-care, ${ }^{\text {iii }}$ ANOVA Health, ${ }^{\text {iv } \text { CHAPS, }}{ }^{v}$ CIDER, vi SACEMA vii and the NHLS vii as well as many University Departments. South Africa has led the way in modelling studies of the prospects for ending the epidemic of HIV, ${ }^{23}$ the impact of HIV on TB, ${ }^{24}$ the importance of spatial heterogeneity, ${ }^{25}$ and agent-based models to better understand the dynamics of the epidemicix ${ }^{26}$ Important trials of the impact of voluntary medical male circumcision (VMMC), ${ }^{11}$ vaginal microbicides, ${ }^{13}$ and community based behaviour change ${ }^{17,27-32}$ interventions, have been and are being conducted in South Africa. Key papers have been published in the social sciences concerning peoples' beliefs about HIV and the role of migration in spreading infection and sustaining the epidemic. ${ }^{33-36}$ The Human Sciences Research Council (HSRC) has carried out a number of important surveys including data on HIV but also on behaviour and other risk factors for infection. ${ }^{\mathrm{x}}$

In spite of the slow start, South Africa rolled-out ART on a massive scale and has the greatest number of people on ART of any country. Following the guidelines of the World Health Organization, ART was recommended in the public-sector for those with a CD4+ cell count below $200 / \mu \mathrm{L}$ in $2002,350 / \mu \mathrm{L}$ in $2009,500 / \mu \mathrm{L}$ in 2012 and for everyone infected with HIV in $2015 .{ }^{37}$ In 2016 an estimated 7.1M people in South Africa were infected with HIV, 4.0M were on ART and 3.2M were virally suppressed. ${ }^{\mathrm{xi}}$ Much still needs to be done to ensure that all those on ART are virally suppressed and all those that are not on ART are started on treatment. However, if the roll-out of ART continues at the present rate there is every reason to believe that, by 2020, South Africa will reach the UNAIDS 90-90-90 target ${ }^{\mathrm{xii}}$ for the percentages of people infected with HIV who know their status, of these that are on ART, and of these that are virally suppressed. By 2030 South Africa should be in a position to end AIDS but not, of course, HIV.

A critical asset in the health system in South Africa is The National Health Laboratory Service. viii This has world class laboratories and expertise in testing for important pathogens, for drug resistance and for gene sequencing. The NHLS provides laboratory services for a range of major trials (Appendix 1).

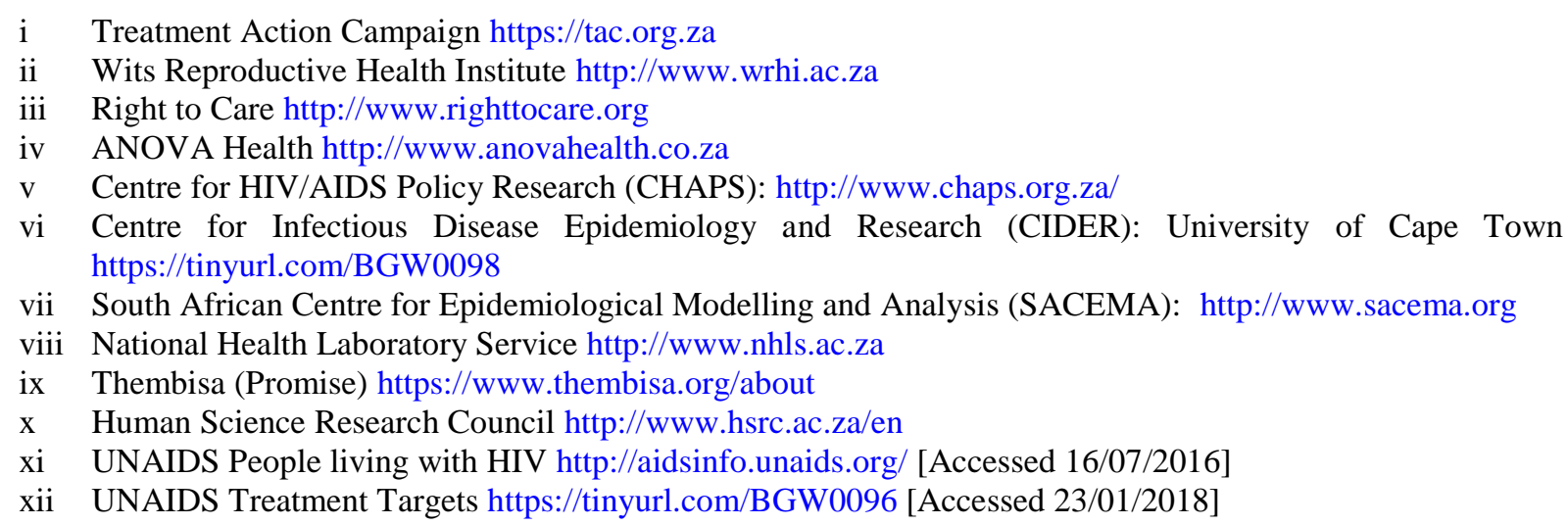




\section{Overview of the epidemic}

A considerable amount of work has gone into measuring, fitting, modelling and analyzing trends in the epidemic of HIV in South Africa and this has provided important insights into the epidemiology of HIV, the development of the epidemic over time, the impact of various approaches to treatment and prevention, the prospects for ending the epidemic and the way in which the epidemic can best be modeled and understood. Here we highlight some of the key aspects of the epidemic of HIV where transmission is mainly due to heterosexual contact.

\section{Trends and projections}

Estimates and projections of time-trends in the prevalence, incidence, mortality and ART coverage in South Africa are based on data on the prevalence of HIV and the coverage of ART assembled and published by UNAIDS. Drawing on our understanding of the epidemiology and natural history of HIV it is possible to estimate and project trends in the incidence of HIV and AIDS-related mortality. Where data on incidence and mortality are available these can be used to refine the epidemiological fits.

In 2017 UNAIDS made a significant change to their estimates of the prevalence of HIV in adults over the preceding ten years. Instead of the prevalence leveling off at a constant level of $16.1 \%$ the new estimates suggest that the prevalence of HIV in adults has increased from $14.8 \%$ to $16.9 \%$ over the last ten years. The change in the estimated trend in the prevalence of HIV over time came about because of the switch from the UNAIDS Spectrum/EPP model, ${ }^{i}$ which was fitted to the overall HIV-prevalence data from ante-natal clinics, suitably adjusted, in the earlier estimates (Figure 1A) to the Thembisa model, ${ }^{\mathrm{ix}, 38}$ which was fitted to agespecific HIV-prevalence data from ante-natal clinics, for the later estimates (Figure 1B). Previously it had been assumed that trends in the prevalence of HIV among women attending ante-natal clinics (ANCs) reflect trends in the adult prevalence of HIV, apart from a scale factor that was fixed over time. Now it is acknowledged that the ANC data are weighted in favour of young women. ${ }^{\text {ii }}$ The revised analysis suggests that the prevalence of HIV is continuing to increase in older women leading to an increase in the adult prevalence of HIV ${ }^{39}$ even if the prevalence in younger women is decreasing. The two estimates of the trend in the overall prevalence of HIV are substantially different but it is not clear which is closer to the actual situation and further studies will be needed to arrive at a consensus.

For the purposes of this discussion we use the earlier data and projections while bearing in mind the possibility that the adult prevalence of HIV is still rising. Fitting a dynamical model to the data in Figure $1 \mathrm{~A}^{6}$ we project the likely impact of ART on HIV and TB assuming that the roll-out of ART is accelerated, starting in 2018, so as to reach the UNAIDS 90-90-90 targets by 2020. The results are shown in Figure 2.

We assume, with the caveat noted above (c.f. Figure 1A and B), that the prevalence of HIV in South Africa has remained steady for the last ten years (Figure 2A). The roll-out of ART has been good and almost half of all the adults infected with HIV are now on ART

\footnotetext{
i UNAIDS http://www.unaids.org/en/dataanalysis/datatools/
}

ii Leigh Johnson, personal communication 
(Figure 2B). If South Africa manages to reach the 90-90-90 targets and then continues to rollout ART at the same rate, the number of people infected with HIV but not on ART (Figure 2C), the HIV-mortality (Figure 2D), the AIDS-related incidence (Figure 2E) and rate at which new people are started on ART (Figure 2F) should all be close to zero by about 2025 and certainly by 2030 .
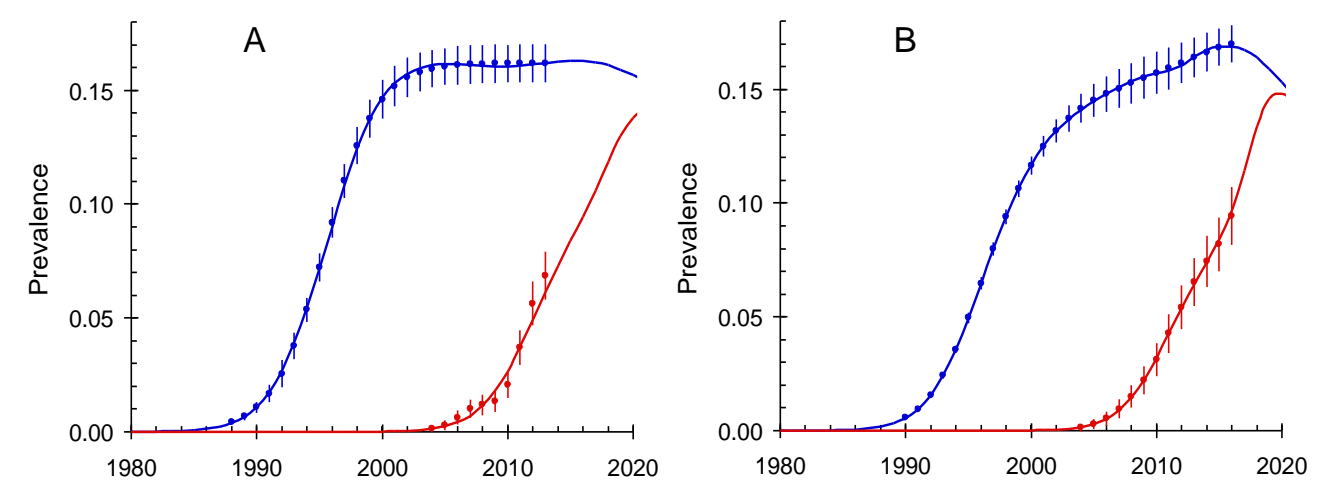

Figure 1. UNAIDS Estimates of the prevalence of HIV and of ART in adults aged 15 years or more. A: 2016 estimates; ${ }^{40}$ B: 2018 estimates. ${ }^{41}$ Blue: HIV prevalence; Red: ART prevalence.

The epidemic of HIV and the roll-out of ART have both had a substantial impact on TB. 6,24,42 The rise in HIV led to a four-fold increase in the TB notification rates while the rollout of ART has reduced the TB notification rates by a factor of two and should cause the TB notification rate to fall to a little above the pre-HIV rate (Figure $2 \mathrm{G}$ ). It is important to note that $\mathrm{CD} 4{ }^{+}$cell counts increase by a fixed amount, $371 \pm 18 / \mu \mathrm{L}$, irrespective of the $\mathrm{CD} 4^{+}$cell counts at the start of treatment, ${ }^{43}$ and to maximize the recovery of the CD4 ${ }^{+}$cells and therefore the benefit to individual patients, people infected with HIV need to start ART as soon as possible after infection. Finally, the data do not provide any evidence that the levels of risk behaviour have changed over the course of the epidemic (Figure $2 \mathrm{H}$ ).

There are, however, two important caveats. First, if it is the case that the prevalence of HIV is rising as suggested by the data in Figure 1B it will be more difficult, but still possible, to end the epidemic provided that the ART coverage is increased to $90-90-90$ by about 2020 and that the roll-out of ART continues at about the same rate after that. Second, the model assumes an average overall level of risk behaviour whereas there will be some high risk, hard to reach, probably marginalized groups of people who may continue to transmit the virus. As we approach elimination more focused strategies will be needed to find and provide treatment and support for such people. 

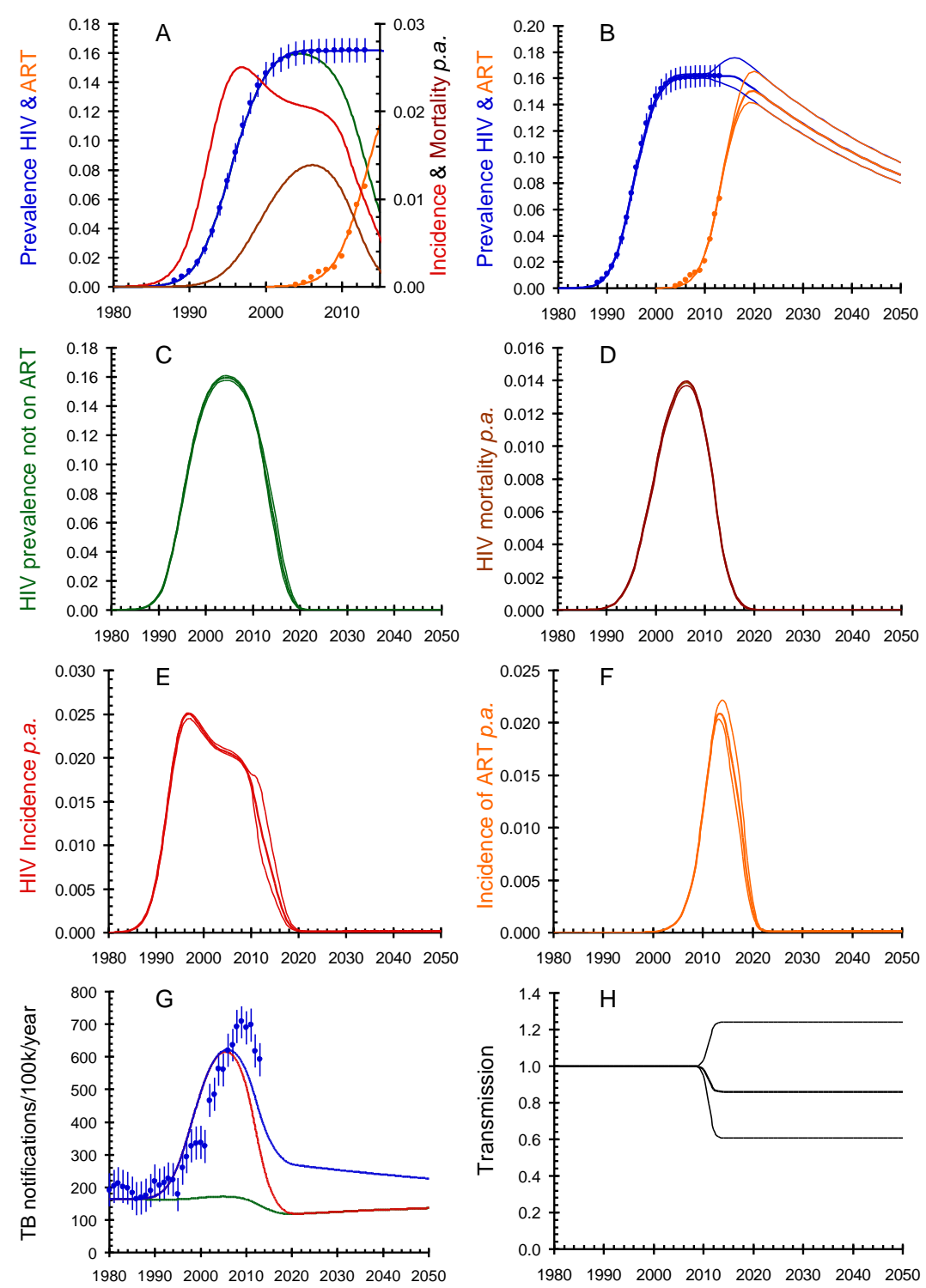

Figure 2. Epidemic trends for HIV and TB in South Africa among adults aged 15 years or more. ${ }^{6}$ A. Blue dots: Prevalence data; Blue line: Fitted prevalence; Green line: Prevalence not on ART; Red line: Incidence of HIV; Brown line: mortality; Orange dots: reported prevalence of ART; Orange line: fitted prevalence of ART. B. Prevalence of HIV and ART. C. Prevalence of HIV not on ART; D. AIDS related mortality; E. HIV incidence; F. Incidence of ART (the rate at which people start ART); G: Blue dots: TB notification rates; Blue line: Fitted TB notification rates; Green line: as blue line for those not on ART; Brown line: HIV negative people. H: Decline in transmission. Error bars and bands are 95\% confidence limits

\section{Cost}

In order to estimate and project the cost of the managing HIV in South Africa we use the estimates in Table 3 allowing for a discount rate of 3\% p.a. ${ }^{42}$ Testing includes the cost of delivering the test and the associated counselling and support; PrEP includes the cost of delivering the drugs; Condoms includes the cost of condoms assuming that a man uses an average of 100 condoms each year. For ART we include the cost of drugs, delivery, and 
support. ${ }^{44}$ For tuberculosis the cost per patient treated is the total number of notified cases divided by the total cost of the TB programme in 2014. ${ }^{45,46}$

Table 1. Estimated costs in 2016 US\$ for the provision of health care for those off and on ART, for each of four clinical stages, delivery of tests, ART, VMMC, PrEP, CD, deaths of young adults, TB treatment, and the Gross Domestic Product. ${ }^{44} \mathrm{We}$ assume a discount rate of $3 \%$ p.a. ${ }^{42}$

\begin{tabular}{lcclc}
\hline & & US\$ & Treatment \& prevention & US\$ \\
\hline Cost of health care per & 1 & 25 & HIV testing per test & 32 \\
person per annum not & 2 & 51 & PrEP per person $p . a$. & 84 \\
on ART by clinical & 3 & 63 & Condoms per person $p . a$. & 5.7 \\
stage & 4 & 108 & VMMC per circumcision & 101 \\
\hline \multirow{2}{*}{ Cost of health care per } & 1 & 48 & ART per person $p . a$. & 274 \\
person per annum on & 2 & 54 & TB treatment per case & 780 \\
ART by clinical stage & 3 & 106 & Deaths per person & $1.1 \mathrm{k}$ \\
& 4 & 132 & GDP per capita $p . a$. & $7.6 \mathrm{k}$ \\
\hline
\end{tabular}

The projected programme costs of managing HIV and treating TB are shown in Figure 3. The cost of VMMC peaks as the backlog of uncircumcised men is dealt with; after that one only needs to circumcise men at the rate at which boys reach adulthood. The cost of PrEP and condoms both peak in 2020 but then decline as the prevalence falls and the number of women needing PrEP and men needing condoms fall with it. In 2006 the cost of deaths due to AIDS peaked at about US\$684M p.a., after that it falls as ART is rolled out and the major cost becomes that of providing ART which is currently running at about US\$1.1Bn p.a.

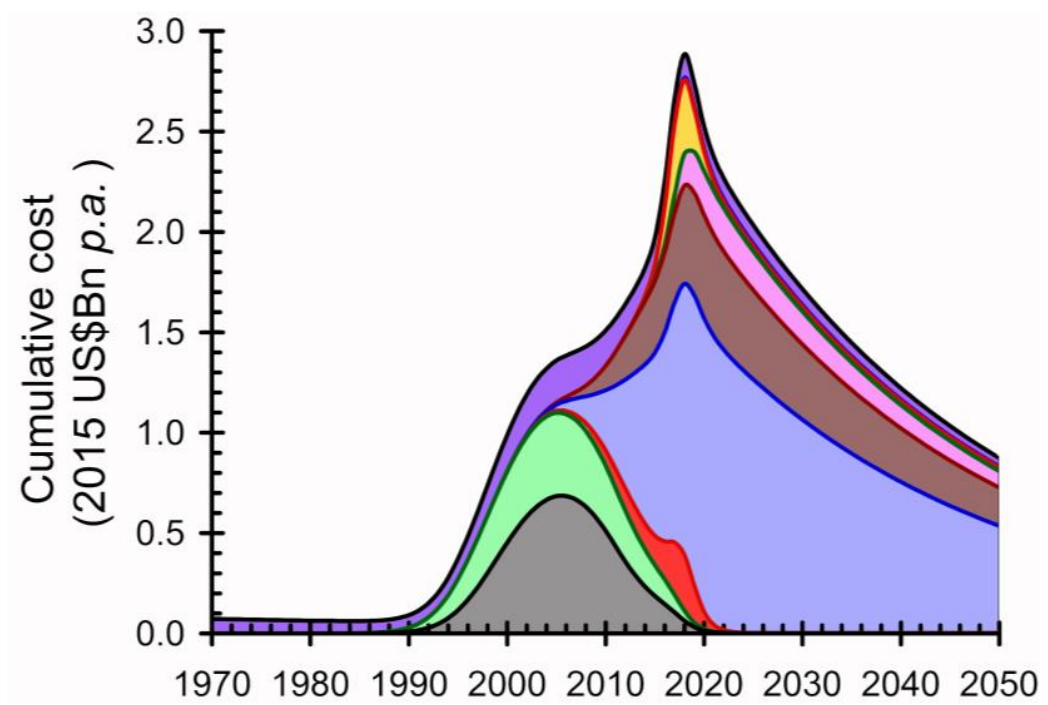

Figure 3. Cumulative annual costs of the different interventions in 2015 US\$. Bottom to Top. Grey: Deaths; Green: Health care not on ART; Red: HIV testing; Blue: ART; Brown: Health care on ART; Pink: Pre-exposure prophylaxis; Yellow: Voluntary medical male circumcision; Purple: Tuberculosis case-finding and treatment. The cost of condom distribution is too small to show. ${ }^{42}$ 
The cost of providing health care to those not on ART is substantial but only until 2020. The cost of providing health care to those on ART is typically about $15 \%$ of the cost of ART. The cost of PrEP is relatively small; the cost of VMMC is significant but only for about five to ten years as the backlog of uncircumcised men is covered. The cost of condom distribution is negligible and the cost of TB treatment is never more than about $5 \%$ of the total cost once the epidemic of HIV has become established.

\section{Spatial heterogeneity}

The epidemic of HIV in South Africa is heterogeneous among risk groups, race, age, gender and location and is driven and sustained by the very high levels of both internal and external migration. ${ }^{33,36,47,48}$ Of particular importance in relation to the distribution of services is the spatial heterogeneity in Figure 4 from an early study. ${ }^{25}$ The highest densities of people living with HIV occur in the three major urban centres: Johannesburg and Soweto in Gauteng, Durban and Cape Town. Particularly high concentrations of people living with HIV are also found in the main mining centres of Carletonville and Welkom as well as in Port Elizabeth. Rural KwaZulu-Natal has high rates of HIV infection but the distribution of people is scattered and uneven making service delivery difficult. However, a focus on the main urban areas, the mining towns, rural KwaZulu-Natal and then parts of the Eastern Cape and Limpopo would include almost all infected people.

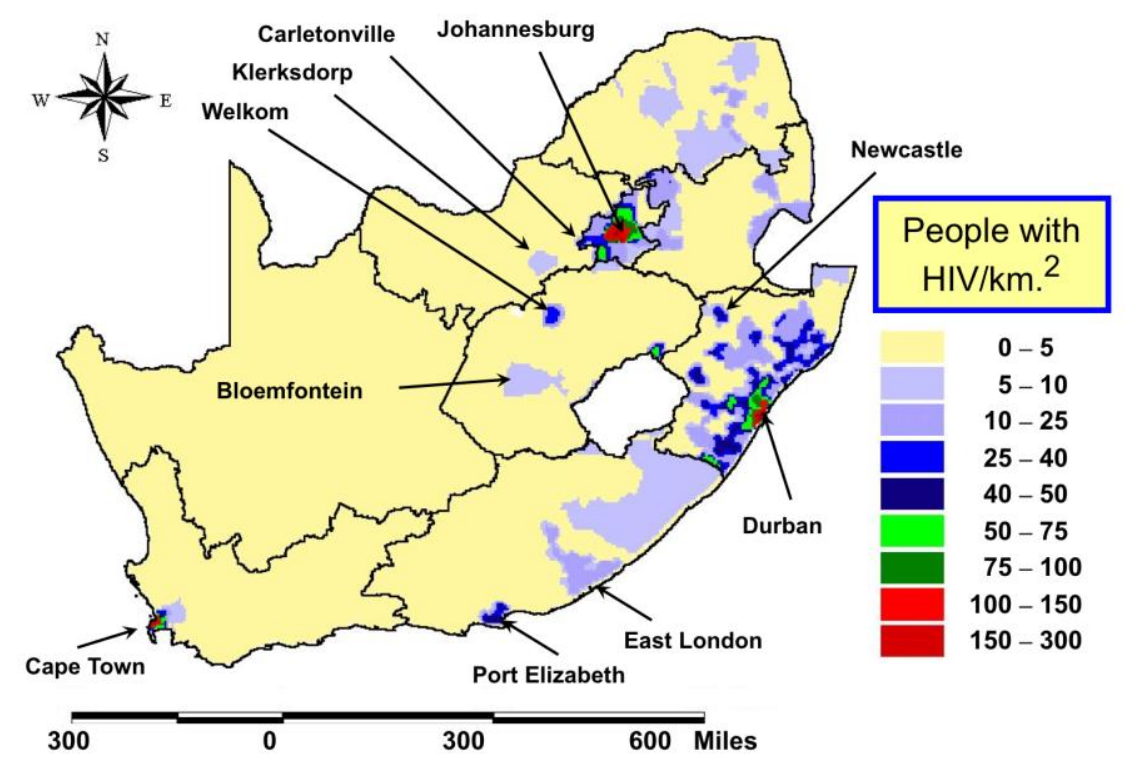

Figure 4. The number of people living with HIV per square kilometre in South Africa in the year 2000. ${ }^{25}$ Bloemfontein has been renamed Mangaung.

\section{National Strategic Plans}

A series of National Strategic Plans (NSPs) have been developed to guide the response to HIV and the Global AIDS Response Progress Report ${ }^{49,50}$ provides a good overview of progress and prospects in 2015. We summarize some of the key milestones here. 
In 2003 the Department of Health published their 'Operational Plan for Comprehensive HIV and AIDS Care, Management and Treatment'. ${ }^{51}$ While the government recognized the importance of treatment there was still a degree of emphasis on the importance of nutritional supplements and traditional medicine. The NSP of 2007-201152 marked a decisive break from the past and called for a massive expansion of the antiretroviral treatment programme that had progressed sporadically since the ART policy was approved by cabinet in 2004 . The plan set the ambitious target to ensure that $80 \%$ of HIV positive people who were eligible for treatment should be on treatment. The estimated cost of reaching this target was R5 Bn in 2007 rising to $\mathrm{R} 12 \mathrm{Bn}$ in 2011.53 While there was still no recognition of the prevention benefits of ART the plan noted that the rapid rollout of the antiretroviral treatment programme would reduce mortality and human suffering while preserving families but presented a huge challenge to the health system operationally and financially.

The NSP of 2012-2016 54,55 proposed a more comprehensive response, an ambitious treatment objective as well as goals linked to expanding prevention and promoting human rights. In particular, the HIV response was linked to key social and structural drivers, set objectives for addressing these drivers and included goals and targets related to TB.

The next NSP55 set the ambitious target that $80 \%$ of HIV positive people eligible for treatment should be on treatment; and remarkably this was achieved by 2016 by which time South Africa had the largest antiretroviral treatment programme in the world with an estimated 3.4 million people on treatment.

By September 2016 the government had adopted a policy to treat all persons who test HIV positive regardless of CD4 count which would further reduce HIV-related morbidity and mortality and significantly reduce TB incidence and mortality. Expanding treatment to all would also have a prevention benefit which is why this NSP emphasized the scale up and improvement in quality of interventions that retain people in care and ensure good adherence and good viral suppression.

The following NSP, for 2017-2022,56 put the focus on prevention, in order to stem the tide of new infections, while calling for expanded prevention interventions that would lead to changes in individual risky sexual behaviour, address early sexual debut, low condom use, multiple concurrent partnerships and alcohol and substance abuse. It also stressed the need to deal with as well as social and structural drivers of risk, such as intergenerational and transactional sex, sexual coercion and gender based violence, circular migration and the breakdown of marriage and the family, youth unemployment, hopelessness and ignorance. (Strategic objectives are in Appendix 4.) South Africa has now embraced the UNAIDS 90-9090 targets $^{57}$ under which $90 \%$ of all people living with HIV will know their HIV status, $90 \%$ of these will receive sustained ART and $90 \%$ of these will be virally suppressed. To these have been added targets for TB, under which $90 \%$ of people with TB should be started on treatment and $90 \%$ of these should be successfully treated, and for STIs under which $70 \%$ of key populations for HIV should have access to services for sexually transmitted infections and HIV, including condoms and lubricants. 57 


\section{Funding the response}

In 2016 an investment case to inform national policy in South Africa was published by a team of technical experts in HIV and TB. ${ }^{44}$ The report found that the investment in HIV and TB related activities in 2013 was R22 billion or US\$2.5 Bn (2013 exchange rate) of which the South Africa government contributed 80\% and the Presidents Emergency Plan for AIDS Relief (PEPFAR) contributed 17\%. The overall breakdown in expenditure is in Table 2.

Table 2. Proportion of the budget spent on each component in 2013.

\begin{tabular}{lc}
\hline Component & Prop. \\
\hline Counselling and testing & 0.06 \\
Care and treatment & 0.40 \\
Prevention & 0.06 \\
Other biomedical & 0.01 \\
Social $\dagger$ & 0.15 \\
TB & 0.18 \\
Other & 0.14 \\
\hline \multirow{\dagger}{\dagger}{ Including key populations, programme } \\
enablers, social behaviour and enablers.
\end{tabular}

A separate analysis of the cost and financing of the response to HIV in South Africa suggested that by 2018 Government expenditure on HIV would have fallen to about US\$1.6 Bn p.a. ${ }^{58}$ with significant cost-savings as efavirenz are replaced by Dolutegravir for first-line treatment of adults. ${ }^{59}$

\section{ART coverage}

The criteria for when to start ART in South Africa have followed the guidelines of the World Health Organization ${ }^{60-62}$ and the recommended CD4 ${ }^{+}$cell counts at which to start treatment among adults have been increased from $200 / \mu \mathrm{L}$ in $2006,350 / \mu \mathrm{L}$ in $2010,500 / \mu \mathrm{L}$ in 2013 and irrespective of $\mathrm{CD}^{+}$cell count in 2016.55,63 Among children, pregnant women and TB patients the recommendation has generally been to start earlier than among adults. 5,64 While the roll-out of ART has been successful and South Africa now has the greatest number of people living with HIV of any country, a more ambitious programme of treatment could have saved many more lives and more money. ${ }^{23}$

\section{Surveillance}

The ante-natal clinic (ANC) surveys allow one to estimate the trends, by province, of the prevalence of HIV among pregnant women. Approximately 30k women are chosen from clinics in each province each year in October. The clinics are chosen randomly with probability proportional to the size of the population in the catchment area. In 2016, following the advice of the World Health Organization, the Department of Health decided to abandon the ANC surveys in favour of using routine patient monitoring. Unfortunately, routine patient monitoring data are not readily available in a form that makes them useful for the analysis of 
trends and in 2017 the Department of Health reinstated the surveys. The most recent survey, directed by Dr. Adrian Puren of the National Health Laboratory Services, was carried out in November 2017 and includes a more extensive set of biological markers including tests for anti-retroviral drugs (ARVs), viral loads, $\mathrm{CD}^{+}{ }^{+}$cell counts, and other sexually transmitted infections (STIs). ${ }^{i}$ The data from the ANC surveys provide the basis for estimates of national trends of the prevalence of HIV in adults. ${ }^{\mathrm{i}}$

In addition to the annual ANC surveys the Human Sciences Research Council (HSRC) has carried out a number of surveys including household surveys, the impact on the health sector and on children, and the impact on mortality. ${ }^{\text {ii }}$ The South African National AIDS Council (SANAC) has produced a number of important reports including successive national strategic plans and a detailed investment plan. iii

\section{Patient monitoring}

The District Health Information System (DHIS) was introduced in South Africa in 1996 and extended to the entire country by 2016 in order to facilitate the collection of aggregated routine data from public health facilities and to support decentralized decision making and health service management. ${ }^{65}$ An evaluation of the DHIS in rural South Africa in $2006^{66}$ found a high perceived work burden associated with data collection and collation but noted that there was little analysis, interpretation or utilization of data and feedback to clinics rarely occurred. The culture of information-use, essential to an information system having an impact at the local level, is weak in these clinics or at the sub-district level. Further training and support is required for the DHIS to function as intended. In 2016 the web-based version WebDHIS, was piloted. ${ }^{65}$

Encouraged by the World Health Organization the South African Department of Health has expressed the intention to rely more on the use of patient monitoring data ${ }^{67}$ and less on ante-natal clinic surveys to assess epidemic trends. The rapid scale-up of antiretroviral therapy in high HIV burden countries has meant that monitoring large cohorts of patients using paper-based systems is no longer practical but many sites do not have the infrastructure and resources needed for electronic medical records (EMR). In South Africa the Western Cape Province has maintained a cohort reporting system since 2003 which began with paperbased systems and guided the development of an electronic data-capture system referred to as Tier.Net ${ }^{68}$ a three-tier approach to monitoring. ${ }^{69}$ Tier 1 is paper-based, Tier 2 is an electronic version of Tier 1, and Tier 3 is a fully connected electronic medical record. Using Tier.net the Western Cape Province has maintained cohort reporting since 2001 and by October 2013 over 175,000 patients had been initiated on ART for the first time, across 227 facilities.

\footnotetext{
i Key documents from the Department of Health, including reports on the annual ANC surveys, can be found at: https://tinyurl.com/BGW0059

ii Key documents from the Human Sciences Research council can be found at https://tinyurl.com/BGW0064

iii Key documents from SANAC can be found at https://tinyurl.com/BGW0065
} 

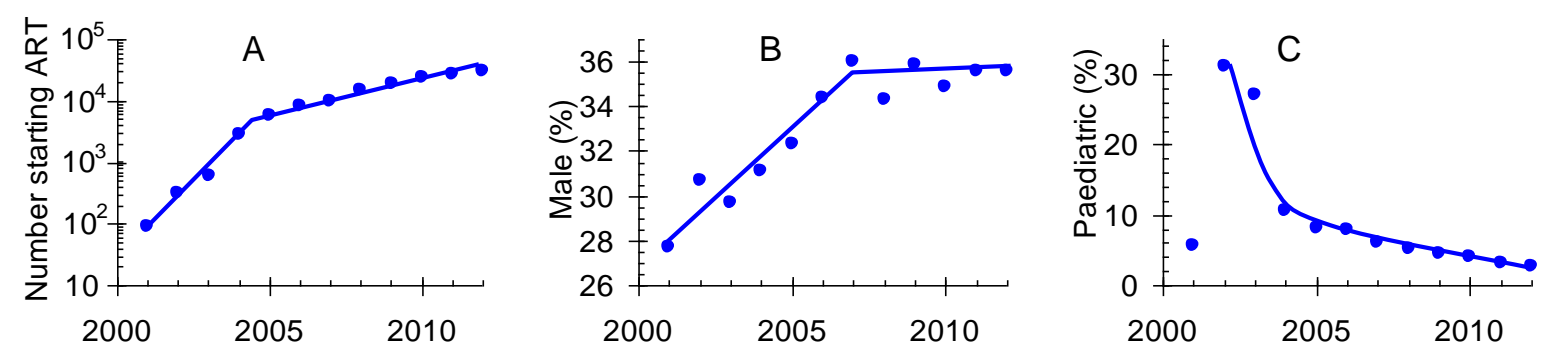

Figure 5. A: The number of people starting ART each year in the Western Cape; B: the proportion that were men and $\mathrm{C}$ : the proportion that were paediatric. ${ }^{69}$

Figure 5A shows that the number of people starting ART in the Western Cape doubled every 10 months from 2001 to 2004 but slowed down in 2005 after which time the number of people starting ART doubled every 2 years and 10 months. It is not clear what drove the change between 2004 and 2005 but there may have been a backlog at the start which it took until 2005 to deal with. Figure 5B shows that there were significantly fewer men than women starting ART particularly when the monitoring started. In a steady state one expects the proportion of infected men to be of the order of $48 \%^{12}$ so that the data suggest that in 2012 HIV-positive women were about twice as likely as men to start treatment. In 2001 and 2002 South Africa focused on mother-to-child transmission and there was a high proportion of paediatric cases but by 2012 paediatric cases only made up $2 \%$ of those starting ART.
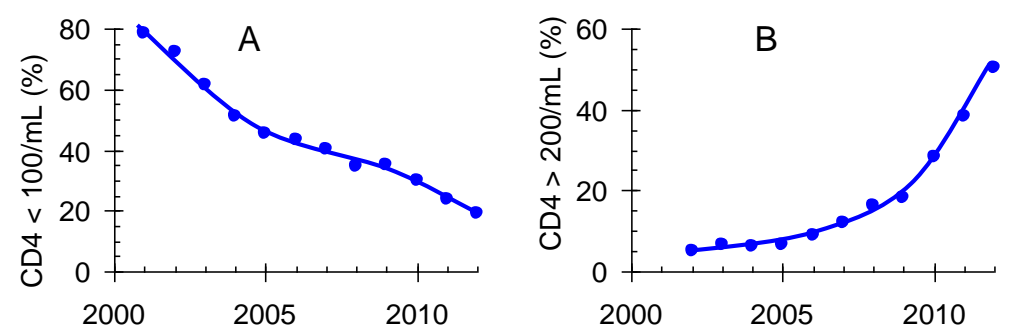

Figure 6. The proportion of people starting ART each year in the Western Cape with a CD4 ${ }^{+}$cell count below $100 / \mu \mathrm{L}$ (A) and above $200 / \mu \mathrm{L}(\mathrm{B}){ }^{69}$

Figure 6 shows that at the start of the treatment roll-out $80 \%$ of people were starting ART very late with a CD4+ cell count below $100 / \mu \mathrm{L}$, while only about $5 \%$ of people were starting ART with a CD4+ cell count greater than 200/ $\mu \mathrm{L}$. By 2012 the situation had improved greatly with about $20 \%$ of people starting ART when their CD4+ cell count was less than $100 / \mu \mathrm{L}$ and about $50 \%$ of people starting ART when their CD4+ cell count was greater than $200 / \mu \mathrm{L}$. The $90-90-90$ target should be to ensure that most people should start ART when their CD 4 cell count is greater than about $500 / \mu \mathrm{L}$ and certainly above $350 / \mu \mathrm{L}$ so there is still room for improvement.

A more worrying trend is the drop off in the number of patients retained in care and the corresponding increase in the loss-to-follow-up with time especially after 4 and 8 years (Figure 7A and B) which the authors attribute to the rapidly increasing number of patients enrolling in care (Figure 5A). ${ }^{69}$ 

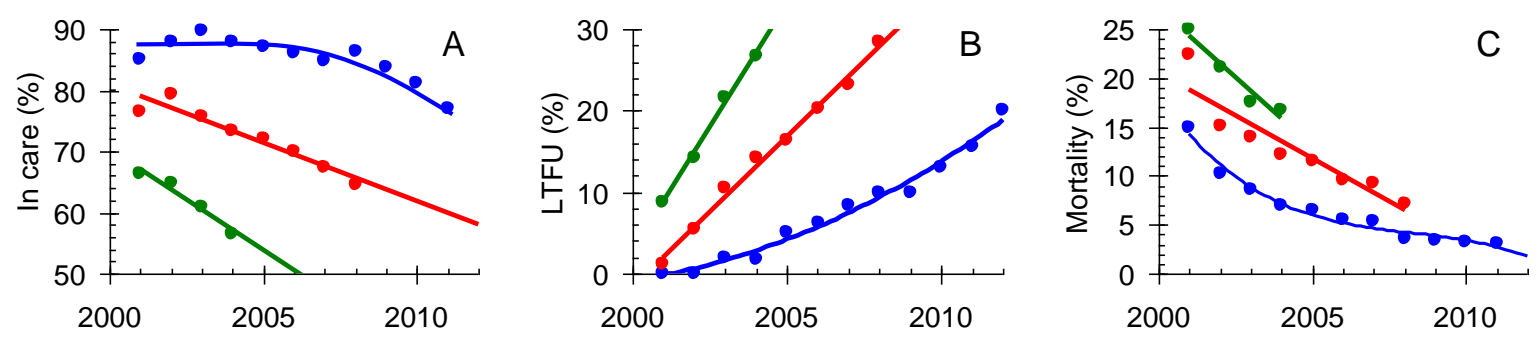

Figure 7. The proportion of people the Western Cape that are in care (A), lost-to-follow up (B) and dead (C) after 1 year (blue), four years (red) and eight years (green) by year at the start of treatment. ${ }^{69}$

The proportion of people on second-line drugs after 1 year on treatment has remained low (Figure 8A; blue line) but reached about $10 \%$ after four years and $20 \%$ after eight years. Rates of viral suppression with a viral load less than $1,500 / \mathrm{mL}$ on the other hand, seem to have stayed consistently high at about $87 \%$. This is significantly better than results obtained from a population-based surveillance system in the uMkhanyakude district of the northern KwaZulu-Natal ${ }^{70}$ where the proportion of those on ART with a viral load below $1,550 / \mathrm{mL}$ had only increased from $30 \%$ in 2011 to $45 \%$ in 2014 leaving considerable room for improvement. The single, most important marker of progress and ultimately success must be to achieve good viral load suppression in as many people infected with HIV as possible. Viral load measurement provides critical information for the management of individuals, the effectiveness of HIV programmes and the coverage, quality and impact of HIV programmes. ${ }^{71-73}$
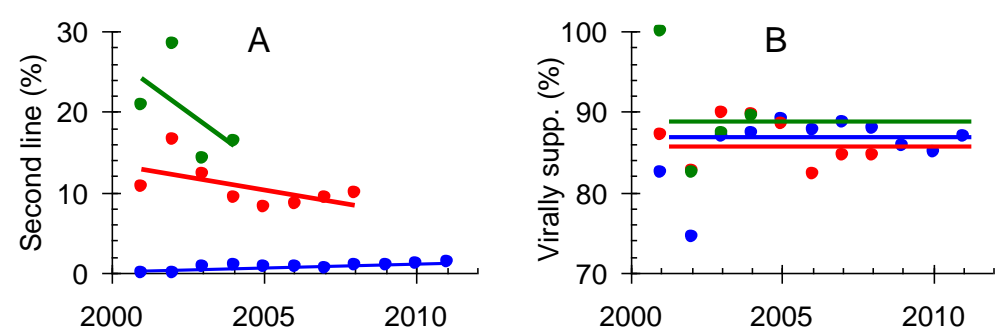

Figure 8. The proportion of people on ART in the Western Cape that are on second line drugs (A) and that are virally suppressed (B) after 1 year (blue), four years (red) and eight years (green) by year at the start of treatment. 69

Tier.Net produces a wealth of important data on the extent of, and performance of, the ART programme in South Africa and highlights some of the problems that need to be dealt with. In 2016 the Measurement and Surveillance of HIV Epidemics (MeSH) Consortium carried out situational analyses to support the development of systems to systematically capture routinely collected health data, to describe and monitor the epidemic for program planning and evaluation for disease control. ${ }^{74}$ The report concluded that the patient-level data collected by Tier.Net and the NHLS do reflect the activities of the national treatment program although neither currently includes diagnosis or pre-ART data and laboratory reporting of HIV diagnosis data at the facility level could be compromised given their limited resources. 
What remains to be shown is the extent to which the data are used to provide feedback to clinics and support to patients.

\section{Linkage to care and patient retention}

In early studies of linkage to care and patient retention it was found that high rates of treatment uptake and adherence could be obtained but the greater problem was the eligibility criteria based on $\mathrm{CD}^{+}$cell counts which meant that most infected people were not eligible for treatment. ${ }^{75-77}$ In 2014 a study was carried out using a population based sample to determine the rate of attrition along the HIV care continuum in the North West Province, South Africa ${ }^{78,79}$ with the results shown in Table 3. Fewer than half of the men and about three-quarters of the women knew their status. Linkage to care was good but retention in care was very poor and of those retained in care only two-thirds of the men were virally suppressed using a rather generous viral load cut-off.

Table 3. Continuum of care, North West Province, 2014. The table gives the percentage of those that tested HIV positive in different categories. ${ }^{78,79}$

\begin{tabular}{lcc}
\hline Condition & Women & Men \\
\hline Know their status & 76 & 48 \\
Ever linked to care & 75 & 44 \\
Retained in care at 1 year & 58 & 33 \\
Viral load < 5k/mL & 50 & 22 \\
\hline
\end{tabular}

A great deal needs to be done to improve linkage to, and retention on care if South Africa is to reach the UNAIDS 90-90-90 goals. In order to understand the risk factors in this regard a pragmatic, randomized controlled trial was conducted in Gauteng and Limpopo provinces between 2013 and 2015;80 the important risk factors for not being retained in care were being under 30 years of age, male, South African (not foreign), living in a urban area, having a high $\mathrm{CD} 4+$ cell count and not having disclosed ones HIV status.

\section{Treatment outcomes}

In a study carried out among patients in Khayelitsha ${ }^{81}$ the median CD4+ cell count was $43 / \mu \mathrm{L}$ at the start of treatment while the mean viral load was $151 \mathrm{k} / \mathrm{mL}$ so that patients were starting treatment with very advanced HIV disease. However, after two years $75 \%$ had a viral load less then $400 / \mu \mathrm{L}, 86 \%$ were still alive and $15 \%$ were on second-line drugs. Reporting from the same study site seven years later in 200782 the median $\mathrm{CD}^{+}{ }^{+}$cell count at the start of treatment had increased to $131 / \mu \mathrm{L}$, the mean viral load at the start of treatment had not changed significantly, and five years after starting ART $84 \%$ were virally suppressed. These results are comparable with the results in the Western Cape (Figure 7 and Figure 8) 


\section{Mortality}

An early study intended to identify deaths from AIDS in South Africa compared causespecific death rates for 1996 and 2000-2001.83 The authors were able to show that among men aged 15 to 64 years $57 \%$ of all deaths were attributable to HIV while among women aged 15 to 59 years $73 \%$ of all deaths were attributable to HIV.

Estimates of the number of deaths attributable to HIV infection all agree that the death rate reached a peak in 2006. However, the estimated number of HIV-related deaths that occurred in that year varied widely. Official statistics suggest that $607 \mathrm{k}^{84}$ people died in South Africa in 2006 and, of these 533,771 were aged 15 years or more. The authors of a recent review of HIV-related deaths ${ }^{85}$ estimated that $283 \mathrm{k}$ ( $53 \%$ of adult deaths) were attributable to HIV-infection. They then compared this to other estimates of AIDS deaths in $2006^{84}$ which ranged from $225 \mathrm{k}(42 \%)$ using the ASSA Model, ${ }^{86}$ 250k (47\%) using the THEMBISA model, ${ }^{85} 270 \mathrm{k}(51 \%)$ in the Global Burden of Disease study, ${ }^{87,88} 350 \mathrm{k}(66 \%)$ using the UNAIDS Spectrum/EPP model, ${ }^{89} 355 \mathrm{k}$ (67\%) from the Institute for Health Metrics and Evaluation. ${ }^{90}$ The authors of the review ${ }^{85}$ attributed much of this variation to misclassification of AIDS deaths associated with different underlying conditions. A recent study of mortality in the medical ward of the Chris Hani-Baragwanath Hospital in Soweto between 2006 and 2009 found that $55 \%$ of all deaths were attributable to HIV 91 close to the estimate from the recent review. ${ }^{85}$ It is of interest to note that this death rate dwarfs even the very high homicide rates in South Africa in 2006 when there were an estimated 19k homicides. ${ }^{92}$

The difficulty in estimating AIDS deaths is partly due to the difficulty of deciding what proportion of deaths from a particular cause, such as TB, should be attributed to HIV infection and without knowing this proportion the models are of little help. While the models ${ }^{85,89}$ all agree that the number of AIDS deaths peaked in 2006 the model estimates of mortality are sensitive to assumptions about survival for people not on anti-retroviral therapy. Using a model ${ }^{6}$ fitted to the time trends in adult prevalence and ART coverage one can show that the estimated number of AIDS deaths in 2006 ranges from 408k if the mean time from infection to death, without ART, is assumed to be 11 years to $237 \mathrm{k}$ if it is assumed to be 16 years. Without a reliable estimate of either AIDS-related deaths or survival after infection without ART, models cannot be used to accurately determine the overall mortality rate due to HIV.

\section{HIV Counselling and Testing}

The entry point for both treatment and prevention will largely be through HIV counselling and testing and the South African government and in March, 2010, Aaron Motsoaledi, the Minister of Health launched the national HIV Counselling and Testing with a view to reaching 15 million people by June $2011^{93}$ taking into account the need to develop clear policy guidelines, protect human rights, ensure confidentiality and informed consent, provide high quality counselling and testing in health facilities, expand community-based, home based and self-testing, ensure good linkage to prevention, care, and treatment services. At the same 
time they stress the importance of documenting and managing test results, re-testing and frequency of HIV testing, maintaining a strong system of monitoring and evaluation, data management and quality assurance. Those at high risk of infection including survivors of sexual assault, prisoners, migrant and mobile populations, people who abuse alcohol or inject drugs, men who have sex with men and sex workers will need special support and attention.

An exhaustive review of models for the scale up of HIV prevention, treatment and care from South Africa and beyond has been developed and presents a large number of models of how to scale up HIV services with an emphasis on prevention and the need to ensure that pregnant women are kept on ART for life. ${ }^{94}$

\section{Community Health Workers}

Managing and controlling HIV remains the most important challenge facing South Africa. However, another key problem facing South Africa is youth unemployment. Training and using community health workers could make a critical contribution to dealing with HIV while creating employment in some of the most marginalized communities and stimulating local economies. The community oriented approach to health care was first developed in South Africa in the 1940s by Sidney and Emily Kark ${ }^{95-98}$ at the Pholela Health Centre in rural KwaZulu-Natal. In 1994 the democratic government was keen to develop a primary health care system inspired in part by the lessons and experience of the much earlier Pholela Project. Unfortunately, as pointed out in a more recent discussion 'adopting a primary health care approach is not a magic bullet that automatically improves the health status of a population... It requires ... medical, social, financial, and political commitment and sacrifice. 99

A somewhat different, but perhaps relevant, project called Zibambele ('doing it for ourselves') was developed to employ marginalized women to fix roads in KwaZulu-Natal;100 in the year 2000 over forty thousand women were receiving R460 (US\$ 60; 2000 exchange rate) each month in return for delivering sixty hours of labour to maintain designated strips of gravel road. In just ten years there were increasingly visible signs of improved household nutrition, people were able to pay school fees, and the forty thousand Zibambele households were organised into 900 savings clubs which had collectively saved more than R13 million (US\$ 1.7M). Even more encouraging was the fact that some of these savings were invested in small-scale enterprises, thus creating more jobs and injecting additional cash into impoverished rural communities. If community health workers can be organized on a similar scale the benefits will extend far beyond the immediate need to control and manage HIV.

More recently101,102 Thomson has worked closely with community health workers in Ekurhuleni covering all aspects of their work, their lives and the social context of their communities (see Appendix 5 for further details). She stresses the importance of not only understanding individual behaviour but also the social structures in which they live and work and their understanding of disease if they are to improve adherence to chronic treatment and improve health outcomes. She outlines an important model for delivering primary health care (PHC) services, via an outreach team of community health workers, at a household level. All too often, the political history of the community and the current violent context is not taken 
into consideration, yet this has a significant impact on peoples' lives and therefore on service implementation and delivery. Her detailed interviews with community health workers, discussing their hopes their fears and their challenges provides a nuanced understanding of what must be done if community health workers are to be effectively engaged in helping to deal with the epidemic of HIV. Most importantly, she argues that taking on community health workers must not be seen as a panacea, it requires structure, administration, training, support, and formal employment. To manage a CHW programme, as Thomson shows (Appendix 5), success will depend on extensive training in a number of health and psycho-social areas, good management, effective support for the CHWs who will be working with marginalised people in sometimes traumatized and often violent social settings, clear job-descriptions and terms of employment, and the payment of salaries not stipends.

\section{Conclusions}

After an uncertain start South Africa now has the biggest HIV-treatment programme in the world. Much of the best and most important science dealing with HIV, AIDS and the associated TB epidemic has been done in South Africa by national scientists and international collaborators. The HIV/AIDS response in South Africa has taken into account all aspects of the epidemic from the molecular and the biological to social and human rights issues while emphasizing the importance of both treatment and prevention. Monitoring and tracking the epidemic and the response to the epidemic has been among the best in the world with annual surveys of the prevalence of HIV among pregnant women run by the Department of Health and the National Health Laboratory Services, periodic surveys of HIV prevalence, incidence and behaviour run by the Human Sciences Research Council, the collection of individual patient data using Tier.Net, and extensive modelling and analysis done by a range of university affiliated groups. South Africa is on track to meet the UNAIDS 90-90-90 targets for the percentage of people who are infected with HIV and know their status, the percentage of these that are on treatment and the percentage of these that are virally suppressed.

Nevertheless, there are several million people living in South Africa, infected with HIV who are not on treatment, and people are still dying of AIDS and AIDS related conditions. The expansion of the treatment programme must continue and prevention made available to those at highest risk. There is much still to be done. As is often the case the 'End Game', that is to say reaching the last, relatively few, infected cases and providing them with the necessary treatment and support to finally end the epidemic, is the hardest task of all. South Africa has an extraordinarily rich collection of data on all aspects of the epidemic and is able to collect and assemble detailed data at an individual level. However, it would appear that using these data to give feedback and support to clinics, to identify problems and weaknesses, to encourage clinics to use the data to provide better help and support to those who are failing treatment and to those that need to start treatment, still needs to be strengthened and improved.

An important future study would be to carry out a survey of feedback to clinics and patients. One could consider taking a random sample of the clinics that were part of the 2017 antenatal clinic survey, which has now been completed, and which is due to report by the 
middle of 2018 (Adrian Puren, personal communication). This would serve two important purposes. First, it would provide information on the way in which clinics are functioning in order to address problems that arise and that are common, explore the extent to which the excellent data that are now being collected using Tier.Net and the DHIS systems are being fed back to clinics, help clinic staff to improve their services and provide better follow-up and treatment support for individual patients. The experience of Malawi will be helpful in this regard. ${ }^{103}$ Second, given the detailed biological data that were collected as part of the 2017 antenatal clinic survey, covering several thousand clinics from all the provinces, one could establish the extent to which the antenatal clinic surveys may be supplemented by, and eventually replaced by, routine patient monitoring data as a way of tracking the epidemic as is being encouraged by the World Health Organization.

\section{Appendix 1. The National Health Laboratory Servicei}

The NHLS provides laboratory testing of biological specimens including gene sequencing. It serves as a reference laboratory for the AIDS Clinical Trials Group ${ }^{104}$ (ACTG) and is the central laboratory for the PASER project. ${ }^{105}$ It monitors HIV-1 drug resistance in the public sector but there is currently no provision for individual patient monitoring. It supports the Wellcome Trust SPARTAC project ${ }^{106}$ to evaluate the use of ARV therapy in HIV-1 recent infections and the A5230 SELECT project ${ }^{107}$ to evaluate optimal second-line regimens. It is the reference laboratory for Africa for the adult ACTG trial and is involved in several retrospective trials looking at HIV-1 drug resistance testing on patients being treated with varying drug regimens. The laboratory carries out sub-typing for the IAVI Protocol $\mathrm{C}$ to the level of circulating subtypes and transmitted drug resistant mutations. The laboratory does genotyping for the NIH CIPRA 'Safeguard the Household' One project will retrospectively monitor for HIV-1 drug resistance in patients with virological failure; the second project will develop more affordable HIV-1 drug resistance testing.

The PASER project, ${ }^{105}$ funded by the Netherlands Government (AIDS fund), is focused on 'bringing resistance testing to Africa'. The NHLS has set up a more affordable populationbased sequencing assay currently being validated against the FDA approved ViroSeq Assay. This project will serve 15 countries in Africa. Two additional laboratories will be set up in East and West Africa with the technology transfer and personnel training occurring at the genotyping unit at the University of the Witwatersrand.

The NHLS also supports the ART-A project, ${ }^{108}$ a European-funded grant developing an accessible and affordable assay to monitor HIV-1 drug resistance, and the SATuRN project which is concerned with surveillance testing on HIV-1 drug resistance in the public sector. ${ }^{109}$ The NHLS carries out resistance testing, data analysis and resistance surveillance guidelines for South Africa.

i National Health Laboratory Service: http://www.nhls.ac.za/?page=hiv_geno\&id=65 


\section{Appendix 2. Treatment Guidelines}

2004: National Antiretroviral Treatment Guidelines. ${ }^{\mathrm{i}}$ Adolescents and adults should start treatment if

1. Their CD4+ cell count is less than $200 / \mu \mathrm{L}$;

2. They are in WHO Clinical Stage 4;

3. They are pregnant.

4. They have TB.

2013: National Antiretroviral Treatment Guidelines. ${ }^{i}$ Adolescents and adults should start treatment if:

1. Their $\mathrm{CD}^{+}{ }^{+}$cell count is less than $350 / \mu \mathrm{L}$;

2. They are in WHO Clinical Stage 3 or 4 ;

3. They are pregnant.

4. They have TB.

2015: National Consolidated Guidelines: for the prevention of mother-to-child transmission of HIV and the management of HIV in children, adolescents and adults. ${ }^{\mathrm{i}}$

Adolescents and adults should start treatment if

1. Their CD4+ cell count is less than $500 / \mu \mathrm{L}$;

2. They are pregnant, breast feeding or within one year post-partum;

3. They have TB or Hepatitis B (HBV);

4. They are under five years of age.

Includes information on drug regimens, care and support, use of viral load monitoring, frequency of repeat testing in pregnant women, changing regimens if failing.

\section{Appendix 3. Mapping details}

The map in Figure 4 was derived from three sources. The human population data were derived from 1. A global coverage of population numbers per image pixel obtained from University of California at Berkeley provided by FAO AGL at 5 minute resolution; 2. A population density coverage at the same resolution from the Consortium for International Earth Science Information Network ${ }^{i}$ (CIESIN: http://www.ciesin.org), derived from data collated by the National Center for Geographic Information and Analysis (NCGIA: http://www.ncgia.ucsb.edu); and 3. Population data from the Intergovernmental Authority on Drought and Development (FAO, 1996). The average of these three estimates was calculated through the raster image manipulation functions within the IDRISI software package by William Wint (personal communication).

\section{Appendix 4. Strategic Objectives of the National Strategic Plan}

The strategic objectives of the NSP 2017-2022, were as follows:

1 Targetted and prioritised approach

i CIESIN http://www.ciesin.org 
2 Tailored combination prevention packages

3 Ensure human dignity and empowerment

4 Universal access to treatment and support services

5 Equitable, tailored, and targeted services to key populations

6 A just and fair society for all

7 Sustainable systems for health and development

8 Investment in cost-effective evidence-based interventions

9 National research agenda

10 Data use for decision-making at all levels

11 Shared responsibility among interconnected and interdependent stakeholders

\section{Appendix 5. The role of community health workers in managing HIV in South Africa ${ }^{i}$}

UNAIDS and WHO support the widespread engagement of Community Health Workers (CHWs) in helping to manage HIV. ${ }^{101}$ This document summarizes lessons learned while working with CHWs in Ekurhuleni and City of Johannesburg since 2013

CHWs have a critical role to play in a primary healthcare system. Living in the communities that they serve they bring health services closer to the community and play an important role in health education and promotion. ${ }^{110}$ Investing in CHWs will help to achieve better health outcomes by finding people in need of support and linking them to the health services while saving costs in other parts of the health system. Creating employment opportunities for women and young adults will result in positive economic returns, address the critical problem of youth unemployment, and inject resources into poor and marginalized communities. ${ }^{110,111}$ Under the right conditions CHWs are passionate about working with and supporting people in their communities and the experience in Ekurhuleni and the City of Johannesburg has shown that they are motivated and committed and provide a critical link to the local health services. ${ }^{102}$

Initially the CHWs found it difficult to work in marginalized communities. The CHWs were often not familiar with the local area and were concerned about traumatic events that they themselves had experienced. The community members were initially unsure of the CHWs' role and were not always welcoming at the start. There was fear of harm on both sides about what the others may do to them. ${ }^{102}$ The CHWs were keen to learn about basic health issues and to develop their ability to provide counselling and especially trauma counselling. Some expressed an interest in providing other basic information such as how to access grants. ${ }^{102}$

\section{Main concerns}

The initial plan was that the CHWs should cover seven core areas:

$\mathrm{i}$ This is written by, and based on, the work of Kirsten Thomson. For more information contact: kirsten@ktconsulting.co.za. 
1. Promote health and prevent illness.

2. Conduct structured household assessments to identify health needs.

3. Provide psychosocial support to community members.

4. Conduct community assessments and mobilize around community needs.

5. Identify and manage minor health problems.

6. Support a continuum of care through service co-ordination with other relevant service providers.

7. Support screening and health promotion programmes in schools and early childhood development centres (ECD).

This overly ambitious plan was intended to improve access to, and delivery of, primary health care for maternal, child and women's health, HIV and TB, chronic, communicable and non-communicable diseases, violence and injury. ${ }^{12-114}$ The initial focus was on household surveys and CHWs often spent a significant part of their time doing administrative work at the facilities. Ways must be found to ensure that the CHWs have clearly defined, manageable and relevant tasks if they are to add value to the provision of, and linkage to, health care and to bee effectively integrated into the healthcare system

CHWs must build relationships with people in the community and, as they get to know the community better and people feel more comfortable in talking to them, they will hear more stories and about situations that go beyond health concerns. Their role includes referring people to various services as well as linking them to care and ensuring adherence to medication.

CHWs are inevitably confronted with domestic violence, child abuse, and community or gang violence. ${ }^{115-117}$ While they are expected to provide psycho-social, supportive and posttrauma counselling 113 they too are exposed to continuous and severe levels of trauma ${ }^{115}$ but there is little relevant literature on this issue and the structures to manage this are not in place. Being linked to the clinic gives CHWs a clearer purpose but community members thought of them as nurses and the CHWs would like to more than just basic health information to the community

The World Health Organisation (WHO) ${ }^{118}$ understands that health professionals often perceive CHWs as low-level assistants and misunderstand their role in promoting and contributing to health in the community. This misunderstanding is reinforced by seeing community health work as voluntary work giving them less status and is evident in the SA healthcare system.

A number of key recommendations are clear.

1. There is a need to engage social workers and enrolled nurses who can work with and support the CHWs.

2. A broader understanding of the South African context of this Department of Health model as well as the engagement of the CHWs within the community is needed.

3. Social workers understand how to engage with, and work in, a community. Some social workers have worked in health and HIV for a period of time and will be able to support health screening. 
4. Training CHWs in monitoring health information can be supported by nurses with inservice training from partners/nurses and/or other team leaders.

5. Many of the issues that the CHWs will face in the community will not be related to health but rather to psychosocial issues

6. Monthly debriefing of community health workers is important and could be facilitated by an external person who has an understanding of trauma, community work, development, health and social issues.

7. Regular debriefing of team leaders must be undertaken and could be facilitated by an external person or someone within the health structure. This would be useful to help process the actual emotional impact of the work as well as strengthen links and structures to support the need and response of the work.

8. If social workers are managing teams, they can assist with debriefing sessions and refer people for psychosocial issues. If these are addressed the overall health of the person and their adherence to medication will also improve.

9. Recognising the high exposure to traumatic experiences that CHWs deal with, this information about context and continuous traumatic stress should form a central part of the education, training and management of CHWs. This could include understanding the broader community context and how this affects the CHWs in their role.

The research carried out for this project ${ }^{102}$ raises several important issues including:

1. The need for a form of certification as a Community Health Worker to recognise the training and work that they have done.

2. The need for a basic knowledge of first aid as CHWs are often asked by community members to assist at scenes of crisis or trauma.

3. Training in community dynamics, working with people from different cultures and with difficult people.

4. Continued development of counselling skills, especially trauma counselling. As community health workers get to know community members better, more information is shared and it would be useful to continue to develop advanced counselling and problemsolving skills and to be able to assist in the initial management of trauma cases that are shared with them or those that they come across in order to contain and appropriately refer.

5. Courses in self-defence, adherence counselling, basics of HIV/AIDS and how to do an HIV test, giving injections and working with children.

6. Information on related conditions such as diabetes and TB.

7. How to approach people and to deal with difficult people or situations, for example when people are drunk, angry or cry uncontrollably.

8. Training in disaster management especially in the case of 'shack fires' which are common.

9. Training in facilitating support groups in the community,

10. Training on how to help people manage and deal with emotions and relationships and how to develop and build up relationships.

11. More information on cleaning and hygiene.

12. Better understanding of social services and the referral processes. 
13. Helping people to manage their finances.

14. People want to be paid a regular salary and be formally employed.

\section{References}

1. Ingram P. Aids figures may be too optimistic. Focus (Journal of the Helen Suzman Foundation) 2000; Available at: https://tinyurl.com/BGW0072.

2. Küstner HG, Swanevelder JP, Van Middelkoop A. National HIV surveillance-South Africa: 1990-1992. South African Medical Journal. 1994; 84: 195-200.

3. Küstner HG, Swanevelder JP, van Middelkoop A. National HIV surveillance in South Africa: 1993-1995. South African Medical Journal. 1998; 88: 1316-20.

4. Swanevelder JP, Küstner HG, van Middelkoop A. The South African HIV epidemic, reflected by nine provincial epidemics: 1990-1996. South African Medical Journal. 1998; 88: 1320-5.

5. Johnson L. Access to antiretroviral treatment in South Africa: 2004-2011. South African Journal of HIV Medicine. 2012; March: 22-7.

6. Williams BG, Gouws E, Somse P, Mmelesi M, Lwamba C, Chikoko T, et al. Epidemiological Trends for HIV in Southern Africa: Implications for Reaching the Elimination Targets. Current HIV/AIDS Reports. 2015; 12: 1-11.

7. Lawson L. Side Effects. Cape Town: Double Story Books; 2008.

8. $\quad$ Specter M. The AIDS Denialists. The New Yorker. March 12, 2007.

9. Goga AE, Jackson DJ, Singh M, Lombard C 2015. Population-level Effectiveness of WHO PMTCT Option A, South Africa: 2012-2013. Cape Town: South African Medical Research Council and National Department of Health of South Africa.

10. Coetzee D, Hilderbrand K, Boulle A, Draper B, Abdullah F, Goemaere E. Effectiveness of the first district-wide programme for the prevention of mother-to-child transmission of HIV in South Africa. Bulletin of the World Health Organization. 2005; 83: 489-94.

11. Auvert B, Taljaard D, Lagarde E, Sobngwi-Tambekou J, Sitta R, Puren A. Randomized, controlled intervention trial of male circumcision for reduction of HIV infection risk: The ANRS 1265 trial. PLoS Medicine. 2005; 2: e298.

12. Williams BG, Lloyd-Smith JO, Gouws E, Hankins C, Getz WM, Hargrove J, et al. The potential impact of male circumcision on HIV in sub-Saharan Africa. PLoS Medicine. 2006; 3: e262.

13. Abdool Karim QA, Abdool Karim SS, Frohlich JA, Grobler AC, Baxter C, Mansoor LE, et al. Effectiveness and safety of tenofovir gel, an antiretroviral microbicide, for the prevention of HIV infection in women. Science. 2010; 329: 1168-74.

14. Williams BG, Abdool Karim SS, Abdool Karim QA, Gouws E. Epidemiological Impact of Tenofovir Gel on the HIV Epidemic in South Africa. Journal of Acquired Immune Deficiency Syndromes. 2011; 58: 207-10. 
15. Campbell C, Williams B. Understanding the Impact of a Community-led HIV Prevention Program in South Africa: Context, Conceptual Framework and Methodology. Australian Journal of Primary Health. 1999; 5: 9-22.

16. Williams B, Campbell C. Community mobilization as an HIV prevention strategy: challenges and obstacles. Sexual Health Exchange. 1999: 4-6.

17. Williams BG, MacPhail C, Campbell C, Taljaard D, Gouws E, Moema S, et al. The Carletonville-Mothusimpilo Project: limiting transmission of HIV through communitybased interventions. South African Journal of Science. 2000; 96: 351-9.

18. Campbell CM, MacPhail C, Mzaidume Z 2001. Peer education and community mobilisation for HIV prevention: lessons from Carletonville, South Africa. London: Department for International Development (United Kingdom) April 2001.

19. Simon-Meyer J 2001. Mothusimpilo, "Helping with Life": An HIV/AIDS Good Practice Case Study of a Community-based HIV/AIDS Prevention Programme. Pretoria: National Population Unit, Department of Social Development, Department of Health, South Africa 28 February 2001.

20. Campbell C, Mzaidume Y. How can HIV be prevented in South Africa? A social perspective. British Medical Journal. 2002; 324: 229-32.

21. Corbett EL, Charalambous S, Fielding K, Clayton T, Hayes RJ, De Cock KM, et al. Stable incidence rates of tuberculosis (TB) among human immunodeficiency virus (HIV)-negative South African gold miners during a decade of epidemic HIV-associated TB. Journal of Infectious Diseases. 2003; 188: 1156-63.

22. Hargrove JW, Humphrey JH, Mutasa K, Parekh BS, McDougal JS, Ntozini R, et al. Improved HIV-1 incidence estimates using the BED capture enzyme immunoassay. AIDS. 2008; 22: 511-8.

23. Granich RM, Gilks CF, Dye C, De Cock KM, Williams BG. Universal voluntary HIV testing with immediate antiretroviral therapy as a strategy for elimination of HIV transmission: a mathematical model. Lancet. 2008; 373: 48-57.

24. Williams BG, Granich R, De Cock K, Glaziou P, Sharma A, Dye C. Antiretroviral therapy for tuberculosis control in nine African countries. Proceedings of the National Academy of Sciences USA. 2010; 107: 19485-89.

25. Williams BG, Gouws E. The epidemiology of human immunodeficiency virus in South Africa. Philosophical Transactions of the Royal Society of London Series B: Biological Sciences. 2001; 356: 1077-86.

26. Johnson LF, Dorrington RE. The demographic and epidemiological impact of HIV/AIDS treatment and prevention programmes: an evaluation based on the ASSA 2000 model. Demographic Association of Southern Africa Conference; 2002.

27. Campbell CA. Male gender roles and sexuality: implications for women's AIDS risk and prevention. Social Science and Medicine. 1995; 41: 197-210. 
28. Campbell C. Migrancy, masculine identities and AIDS: the psychosocial context of HIV transmission on the South African gold mines. Social Science and Medicine. 1997; 45: 273-81.

29. Campbell CM, Williams BG. Managing disease on the goldmines: 'work-related' and 'non-work-related' diseases. South African Medical Journal. 1998; 88: 789-95.

30. Campbell C, Williams B. Beyond the biomedical and behavioural: towards an integrated approach to HIV prevention in the southern African mining industry. Social Science and Medicine. 1999; 48: 1625-39.

31. Campbell C. Selling sex in the time of AIDS: the psycho-social context of condom use by sex workers on a Southern African mine. Social Science and Medicine. 2000; 50: 479-94.

32. Williams BG, Taljaard D, Campbell CM, Gouws E, Ndhlovu L, Van Dam J, et al. Changing patterns of knowledge, reported behaviour and sexually transmitted infections in a South African gold mining community. AIDS. 2003; 17: 2099-107.

33. Hargrove J. Migration, mines and mores: the HIV epidemic in southern Africa. South African Journal of Science. 2008; 104: 53-61.

34. Lurie M, Harrison A, Wilkinson D, Abdool Karim SS. Circular migration and sexual networking in rural KwaZulu/Natal: Implications for the spread of HIV and other sexually transmitted diseases. Health Transition Review. 1997; 7: 15-27.

35. Lurie M, Williams BG, Zuma K, Mkaya-Mwamburi D, Garnett GP, Sweat MD, et al. Who infects whom? HIV-1 concordance and discordance among migrant and nonmigrant couples in South Africa. AIDS. 2003; 17: 2245-52.

36. Lurie MN, Williams BG, Zuma K, Mkaya-Mwamburi D, Garnett G, Sturm AW, et al. The impact of migration on HIV-1 transmission in South Africa: a study of migrant and non-migrant men and their partners. Sexually Transmitted Diseases. 2003; 30: 149-56.

37. Granich R, Williams B, Montaner J, Zuniga JM. 90-90-90 and ending AIDS: necessary and feasible. The Lancet. 2017; 390: 341.

38. Johnson LF, Dorrington RE 2017. Modelling the impact of HIV in South Africa's provinces: 2017 update. Centre for Infectious Disease Epidemiology and Research, Cape Town September 2017.

39. Hargrove JW, Humphrey JH, Mahomva A, Williams BG, Chidawanyika H, Mutasa K, et al. Declining HIV prevalence and incidence in perinatal women in Harare, Zimbabwe. Epidemics. 2011; 3: 88-94.

40. UNAIDS. AIDSInfo Online Database. 2016 Accessed: 17 July 2016; Available at: http://aidsinfo.unaids.org/.

41. UNAIDS. AIDSInfo online database. 2018 Accessed: January 30, 2018; Available at: http://aidsinfo.unaids.org/. 
42. Williams BG, Gupta S, Wollmers M, Granich R. Progress and prospects for the control of HIV and tuberculosis in South Africa: a dynamical modelling study. The Lancet Public Health. 2017; 2: e223-e30.

43. Gras L, Kesselring AM, Griffin JT, van Sighem AI, Fraser C, Ghani AC, et al. CD4 cell counts of 800 cells $/ \mathrm{mm}^{3}$ or greater after 7 years of highly active antiretroviral therapy are feasible in most patients starting with 350 cells $/ \mathrm{mm}^{3}$ or greater. Journal of Acquired Immune Deficiency Syndromes and Human Retrovirology. 2007; 45: 183-92.

44. SANAC 2016. South African HIV and TB Investment Case: Reference Report, Phase 1. March 2016. Pretoria: South African National AIDS Council (SANAC) Available at: https://tinyurl.com/BGW0092.

45. World Health Organization 2015. Global Tuberculosis Control: Surveillance, Planning, Financing. Geneva: World Health Organization Available at: https://tinyurl.com/BGW0099.

46. Laurence YV, Griffiths UK, Vassall A. Costs to Health Services and the Patient of Treating Tuberculosis: A Systematic Literature Review. PharmacoEconomics. 2015; 33: 939-55.

47. Lurie MN, Williams BG. Migration and health in Southern Africa: 100 years and still circulating. Health Psychology and Behavioral Medicine. 2014; 2:1: 34-40.

48. Williams BG, Gouws E, Lurie M, Crush J 2002. Spaces of Vulnerability: Migration and HIV/AIDS in South Africa. Cape Town: Queens University, Kingston, Canada.

49. UNAIDS 2011. Global HIV/AIDS Response: Epidemic update and health sector progress towards Universal Access. Progress Report. Geneva: UNAIDS/WHO/UNICEF.

50. UNAIDS 2012. Global AIDS Response: Progress Reporting 2012 Geneva Available at: https://tinyurl.com/BGW0074.

51. Mbewu A, Simelela N, For the task team 2005. Operational Plan for Comprehensive HIV and AIDS Care, Management and Treatment for South Africa 19 November. Pretoria: Department of Health, South Africa Available at: https://tinyurl.com/BGW0075.

52. Anonymous 2007. HIV and AIDS and STI Strategic Plan for South Africa, 2007-2011. Pretoria: Government of South Africa; Office of the Deputy President.

53. Cleary S, Blecher M, Boulle A, Dorrington R, Darkoh E, Bogopane-Zulu H 2007. The costs of the National Strategic Plan on HIV and AIDS \& STIs 2007-2011. Pretoria: Department Available at: https://tinyurl.com/BGW0076.

54. SANAC 2011. National Strategic Plan on HIV \& AIDS, STIs and TB: 2012-2016. Pretoria: South African National AIDS Council (SANAC) Available at: https://TinyURL.com/BGW0089. 
55. SANAC 2014. Progress Report on the National Strategic Plan for HIV, TB and STIS (2012-2016). Pretoria: South African National AIDS Council (SANAC) Available at: https://tinyurl.com/BGW0090.

56. SANAC 2016. Let Our Actions Count: National Strategic Plan on HIV \& AIDS, STIs and TB: 2017-2022. Pretoria: South African National AIDS Council (SANAC) Available at: https://tinyurl.com/BGW0093.

57. UNAIDS 2016. 90-90-90 On the right track towards the global target. Available at: http://www.unaids.org/en/resources/documents/2016.

58. Meyer-Rath G, Johnson LF, Pillay Y, Blecher M, Brennan AT, Long L, et al. Changing the South African national antiretroviral therapy guidelines: The role of cost modelling. Plos One. 2017; 12: e0186557.

59. Meyer-Rath G, Masuku S. Cost impact of replacing efavirenz with dolutegravir in firstline antiretroviral treatment of adults in South Africa. Health Economics and Epidemiology Research Office, HE²RO Policy Brief Number 18. Johannesburg. October 2017.

60. World Health Organization. Scaling up Antiretroviral Therapy in Resource Limited Settings: Guidelines for a Public Health approach. Geneva: World Health Organization; 2002.

61. World Health Organization 2004. Scaling up antiretroviral therapy in resource-limited settings: Treatment guidelines for a public health approach. Geneva.

62. Organization WH 2010. Antiretroviral therapy for HIV infection in adults and adolescents Recommendations for a public health approach. Geneva Available at: www.who.int/hiv/pub/arv/adult2010/en/.

63. Adam MA, Johnson LF. Estimation of adult antiretroviral treatment coverage in South Africa. South African Medical Journal. 2009; 99: 661-7.

64. Moorhouse M. Unmet needs and challenges of current ART in South Africa. Wits Reproductive Health Institute and South African HIV/AIDS Clinicians Society 21 November 2015.

65. Cabuko M. WEB-DHIS Transition Strategy: Presentation to NHISSA. 6-7 July, 2016; Available at: https://tinyurl.com/BGW0068.

66. Garrib A, Stoops N, McKenzie A, Dlamini L, Govender T, Rohde J, et al. An evaluation of the District Health Information System in rural South Africa. South African Medical Journal. 2008; 98: 549-52.

67. Organization WH 2017. Consolidated Guidelines on Person Centred HIV Patient Monitoring and Case Based Surveillance. Geneva: World Health Organization Available at: https://tinyurl.com/BGW0100. 
68. Westley E, Green ES, Tarr G, Hawes SE 2014. South Africa's 3-tiered antiretroviral treatment monitoring system. University of Washington, for the Bill and Melinda Gates Foundation.

69. Osler M, Hilderbrand K, Hennessey C, Arendse J, Goemaere E, Ford N, et al. A threetier framework for monitoring antiretroviral therapy in high HIV burden settings. Journal of the International AIDS Society. 2014; 17: 18908-n/a.

70. Vandormael A, Bärnighausen T, Herbeck J, Tomita A, Phillips A, Pillay D, et al. Longitudinal trends in the prevalence of detectable HIV viraemia: Population-based evidence from rural KwaZulu-Natal, South Africa. Clinical Infectious Diseases. 2017: cix976.

71. El-Sadr WM, Rabkin M, Nkengasong J, Birx DL. Realizing the potential of routine viral load testing in sub-Saharan Africa. Journal of the International AIDS Society. 2017; 20: e25010.

72. Ellman TM, Alemayehu B, Abrams EJ, Arpadi S, Howard AA, El-Sadr WM. Selecting a viral load threshold for routine monitoring in resource-limited settings: optimizing individual health and population impact. Journal of the International AIDS Society. 2017; 20: e25007.

73. Lecher S, Williams J, Fonjungo PN, Kim AA, Ellenberger D, Zhang G, et al. Progress with Scale-Up of HIV Viral Load Monitoring: Seven Sub-Saharan African Countries, January 2015-June 2016 Morbidity and Mortality Weekly Report. 2016; 65: 1332-5.

74. MESH 2016. HIV Case Based Surveillance \& Patient Tracking Systems Results from Four Situational Assessments in High Burden, Low-Resourced Countries. Measurement and Surveillance of HIV Epidemics (MeSH) Consortium Available at: https://tinyurl.com/BGW0077.

75. Myer L, Phillips T, Manuelli V, McIntyre J, Bekker L-G, Abrams EJ. Implementation and Operational Research: Evolution of Antiretroviral Therapy Services for HIVInfected Pregnant Women in Cape Town, South Africa. Journal of Acquired Immune Deficiency Syndromes. 2015; 69: e57-e65.

76. Clouse K, Pettifor AE, Maskew M, Bassett J, Van Rie A, Behets F, et al. Patient Retention From HIV Diagnosis Through One Year on Antiretroviral Therapy at a Primary Health Care Clinic in Johannesburg, South Africa. Journal of Acquired Immune Deficiency Syndromes. 2013; 62: e39-e46.

77. van Rooyen H, Barnabas RV, Baeten JM, Phakathi Z, Joseph P, Krows M, et al. High HIV Testing Uptake and Linkage to Care in a Novel Program of Home-Based HIV Counseling and Testing With Facilitated Referral in KwaZulu-Natal, South Africa. Journal of Acquired Immune Deficiency Syndromes. 2013; 64: e1-e8.

78. Lippman SA, Neilands TB, MacPhail C, Peacock D, Maman S, Rebombo D, et al. Community Mobilization for HIV Testing Uptake: Results From a Community Randomized Trial of a Theory-Based Intervention in Rural South Africa. Journal of Acquired Immune Deficiency Syndromes. 2017; 74: S44-S51. 
79. Lippman SA, Shade SB, El Ayadi AM, Gilvydis JM, Grignon JS, Liegler T, et al. Attrition and Opportunities Along the HIV Care Continuum: Findings From a Population-Based Sample, North West Province, South Africa. Journal of Acquired Immune Deficiency Syndromes. 2016; 73: 91-9.

80. Dorward J, Mabuto T, Charalambous S, Fielding KL, Hoffmann CJ. Factors associated with poor linkage to HIV care in South Africa: secondary analysis of data from the Thol'impilo trial. Journal of Acquired Immune Deficiency Syndromes. 2017; 76: 453-60.

81. Coetzee D, Hildebrand K, Boulle A, Maartens G, Louis F, Labatala V, et al. Outcomes after two years of providing antiretroviral treatment in Khayelitsha, South Africa. AIDS. 2004; 18: 887-95.

82. Boulle A, Van Cutsem G, Hilderbrand K, Cragg C, Abrahams M, Mathee S, et al. Seven-year experience of a primary care antiretroviral treatment programme in Khayelitsha, South Africa. AIDS. 2010; 24: 563-72.

83. Groenewald P, Nannan N, Bourne D, Laubscher R, Bradshaw D. Identifying deaths from AIDS in South Africa. AIDS. 2005; 19: 193-201.

84. Anonymous 2008. Mortality and causes of death in South Africa, 2006: Findings from death notification. Pretoria: Statistics South Africa, Private Bag X44, Pretoria 0001 Available at: https://tinyurl.com/BGW0085.

85. Bradshaw D, Msemburi W, Dorrington R, Pillay-van Wyk V, Laubscher R, Groenewald $\mathrm{P}$, et al. HIV/AIDS in South Africa: how many people died from the disease between 1997 and 2010? AIDS. 2016; 30: 771-8.

86. Johnson LF, Dorrington RE. Modelling the demographic impact of HIV/AIDS in South Africa and the likely impact of interventions. Demographic Research. 2006; 14: 541-74.

87. Lozano R, Naghavi M, Foreman K, Lim S, Shibuya K, Aboyans V, et al. Global and regional mortality from 235 causes of death for 20 age groups in 1990 and 2010: a systematic analysis for the Global Burden of Disease Study. Lancet Global Health. 2012; 380: 2095-128.

88. GBD 2013 Mortality and Causes of Death Collaborators. Global, regional, and national age-sex specific all-cause and cause-specific mortality for 240 causes of death, 19902013: a systematic analysis for the Global Burden of Disease Study 2013. Lancet Global Health. 2015; 385: 117-71.

89. Stover J, Brown T, Marston M. Updates to the Spectrum/Estimation and Projection Package (EPP) model to estimate HIV trends for adults and children. Sexually Transmitted Infections. 2012; 88: i11-6.

90. Birnbaum J, Murray CJ, Lozano R. Exposing misclassified HIV/AIDS deaths in South Africa. Bulletin of the World Health Organization. 2011; 89: 278-85.

91. Black A, Chibrawara T, Gill Z, Kubanje M, Sitas F, Williams BG. HIV-Attributed Causes of Death at the Chris Hani Baragwanath Hospital, South Africa. In preparation. 2018. 
92. Williams BG. Apartheid's legacy: Politics and Public Health. Unpublished 2018 Available at: https://TinyURL.com/BGW0086.

93. Anonymous 2015. National HIV Counselling and Testing Policy Guidelines. Pretoria: Department of Health Available at: https://tinyurl.com/BGW0078.

94. Youngleson M. Tried and Tested: Models for the scale up of HIV prevention, treatment and care from South Africa and beyond. Pretoria: South African National Department of Health; 2010.

95. Kark SL. The social pathology of syphilis in Africans. South African Medical Journal. 1949; 23: 77-84.

96. Bam N, Marcus T, Hugo J, Kinkel J. Conceptualizing Community Oriented Primary Care (COPC)-the Tshwane, South Africa. Health post model. African Journal of Primary Health Care and Family Medicine. 2013; 5: 1-3.

97. Geiger HJ. Community-Oriented Primary Care: The Legacy of Sidney Kark. American Journal of Public Health. 1993; 83: 946.

98. Susser M. A South African Odyssey in Community Health: A Memoir of the Impact of the Teachings of Sidney Kark. American Journal of Public Health. 1993; 83: 1039-42.

99. Phillips H. The Return of the Pholela Experiment: Medical History and Primary Health Care in Post-Apartheid South Africa. American Journal of Public Health. 2014; 104: 1872-6.

100. Ginsburg D. Zibambele: Creating jobs, managing health. SACEMA Quarterly 2010 Accessed June Available at: https://tinyurl.com/BGW0081.

101. Thomson K. The value of the community health worker in the South African health care system. SACEMA Quarterly 2016 Available at: https://tinyurl.com/BGW0082.

102. Thomson K Exploring the experience of Community Health Workers operating in contexts where trauma and its exposure are continuous Master of Science: University of the Witwatersrand. Johannesburg; 2014.

103. Williams BG 2017. HIV and Patient Monitoring in Malawi. Report written for the World Health Organization, Geneva. South African Centre for Epidemiological Modelling and Analysis Available at: https://tinyurl.com/BGW0083.

104. ACTG: AIDS Clinical Trials Group. Available at: https://actgnetwork.org.

105. PASER: Pan-African Studies to Evaluate Resistance. Available at: https://www.aighd.org/project/paser/.

106. SPARTAC: Short Pulse Anti-Retroviral Therapy at HIV Seroconversion. Available at: https://tinyurl.com/BGW0087.

107. La Rosa AM, Harrison LJ, Taiwo B, Wallis CL, Zheng L, Kim P, et al. Raltegravir in second-line antiretroviral therapy in resource-limited settings (SELECT): a randomised, phase 3, non-inferiority study. The Lancet HIV. 3: e247-e58. 
108. ART-A Project. Affordable Resistance tests for Africa. Available at: https://www.aighd.org/project/art-a/.

109. Manasa J, Lessells R, Rossouw T, Naidu K, Van Vuuren C, Goedhals D, et al. Southern African Treatment Resistance Network (SATuRN) RegaDB HIV drug resistance and clinical management database: supporting patient management, surveillance and research in southern Africa Database. 2014.

110. Spotlight 2015. Community health workers: A Spotlight in-depth feature Published on 30 November 2015. Available at: https://tinyurl.com/BGW0102.

111. Crigler L, Glenton C, Hodgins S, LeBan K, Lewin S, Perry H, et al. Developing and Strengthening Community Health Worker Programmes at Scale: A Reference Guide for Program managers and policy makers. 2013; Available at: https://tinyurl.com/BGW0103.

112. Anonymous 2011. Report on the progress of PHC Re-engineering: Report to the National Health Council. Pretoria: Department of Health, South Africa.

113. Anonymous 2011. Provincial guidelines for the implementation of the three streams of PHC Re-engineering. Pretoria: Department of Health, South Africa.

114. Anonymous 2011. Ward based Primary Health Care Outreach Teams: Implementation Toolkit. Pretoria: Department of Health, South Africa.

115. Miller K, Ramussen A. War exposure, daily stressors and mental health in conflict and post-conflict settings: Bridging the divide between trauma-focused and psychosocial frameworks. , 70, 7-16. Social Science and Medicine. 2010; 70: 7-16.

116. Williams S, Williams D, Stein D, Seedat S, Jackson P, Moomal H. Multiple traumatic events and psychological distress: The South Africa stress and health study. . Journal of Traumatic Stress. 2007; 20: 845-55.

117. Lehmann U, Sanders D 2007. Community health workers: What do we know about them? The state of the evidence on programmes, activities, costs and impact on health outcomes of using community health workers. School of Public Health, University of the Western Cape, South Africa.

118. Anonymous 1990. Strengthening the performance of community health workers. Geneva: World Health Organisation.: World Health Organisation. 